\title{
A Right to Vote: A Case Study in Nursing Advocacy for Public Policy Reform
}

\author{
Abe Oudshoorn \\ Arthur Labatt Family School of Nursing, Western University, London, Ontario, Canada \\ Cite as: Oudshoorn, A. (2019). A Right to Vote: A Case Study in Nursing Advocacy for Public Policy \\ Reform. Witness: The Canadian Journal of Critical Nursing Discourse, 1(2), 64-72 \\ https://doi.org/10.25071/2291-5796.27
}

\begin{abstract}
In February 2014, the Government of Canada under Stephen Harper introduced the 'Fair Elections Act'. This reform to the elections act removed provisions for access to voting for individuals lacking certain forms of identification. Noting that this would have a disproportionate impact on people experiencing homelessness, nursing advocates joined with other activists to try to prevent then subsequently overturn this legislation. The purpose of this paper is to explore the $93^{\text {rd }}$ competency of the College of Nurses of Ontario, "Advocates and promotes healthy public policy and social justice," by unpacking a case example of advocacy for voting rights. This paper addresses the challenges faced by nurses in doing public policy advocacy and concludes with lessons learned. Fulfilling our college mandated requirement to be politically active means ensuring that public policies are just, equitable, and reflective of the progressive values of Nursing.
\end{abstract}

Keywords: Nursing, advocacy, rights, voting, political action

Colleges of Nursing across Canada set out competencies required of registered nurses. It is common for these competencies to include advocacy for healthy public policy, such as: " 88 . Advocates for and supports healthy public policy and principles of social justice," (British Columbia College of Nursing Professionals, 2018, pg. 16) and "93. Advocates and promotes healthy public policy and social justice" (College of Nurses of Ontario, 2014, pg. 10). Additionally, the 'Code of Ethics for Registered Nurses' (Canadian Nurses Association, 2017) requires that, "Nurses uphold principles of justice by safeguarding human rights" (pg. 15). Each nursing competency in its simplicity belies the complex skillsets required for enactment and the risk inherent in being incompetent; public policy advocacy is no different. Advocacy is frequently taken-up within the profession as a communication of client needs or concerns. In this modality, the nurse is perceived as an avenue to transmit or amplify issues most often within the interprofessional team. However, a close reading of the afore-mentioned competencies indicates a call for action at the public policy level. This creates a shift from a more comfortable conceptualization of sharing client stories to engaging in political activism. As BuckMcFadyen and MacDonnell warn, "Political activism is a contentious concept within the discipline of nursing, with little agreement on how to define the term and what constitutes

Corresponding Author: Dr. Abe Oudshoorn, Assistant Professor. 
appropriate activist practice within the scope of nursing" (2017, pg. 1). It is therefore conceivable as to why nurses and nursing have been at times tentative in exercising more vocal and more visible advocacy at the level of public policy.

Regardless of the desired change, it has been identified that health professionals by and large are receiving insufficient educational preparation in public policy advocacy (Avolio, 2014; Benton, 2012; Lyons, et al., 2015). Therefore, the purpose of this paper is to present a particular case of nursing advocacy around voting rights to explore both the challenges inherent in this competency and to provide practical suggestions to support nurses who seek to enact public policy advocacy for social justice. Providing recommendations to overcome the challenges of public policy advocacy can begin to fill the gaps in health professional education (Kerr, et al., 2017).

\section{The Context}

The focus of this article is advocacy efforts by nurses to support people who are experiencing homelessness to be able to vote. Homelessness is a social experience that is rich in opportunities for policy advocacy as its existence as a phenomenon is largely determined by social policy (Marcuse, 1988; Sparks, 2017). Preventing homelessness requires structural and systemic reforms (Gaetz \& Dej, 2017). Therefore, nurses working in the homelessness sector see opportunities for advocacy efforts addressing a breadth of failed public policies across a variety of sectors (Crowe $\&$ Baker, 2007). In my own experience working as a nurse with people experiencing homelessness, if we are to be honestly open to assessing the needs of our clients, we will often find the interventions required to meet these needs are more structural than interpersonal. This honest assessment of the root causes of client needs is one source of evidence required to formulate advocacy actions (Barrett-Sheridan, 2009). As health professionals intimately close to the challenges of our clients, we have a privileged position to elevate their concerns to decisionmaking realms (Reutter \& Kushner, 2010). This is not some form of heroic act, but simply an ethical response to our requirement to intervene as needed to promote the health of all people.

Access to voting is guaranteed to every citizen in Section 3 of the 'Canadian Charter of Rights and Freedoms'. However, voter suppression efforts have a long history in liberal democracies and frequently disenfranchise already marginalized populations (Anderson, 2018). As minority and low-income populations on trend vote more liberally, these suppression efforts tend to favour conservative candidates (Anderson, 2018). People experiencing homelessness have been identified as a population at risk of barriers to achieving the right to vote (Ruth, Matusitz, \& Simi, 2017). My personal exposure to the issues of voting amongst individuals experiencing homelessness began in 2004 when I was employed as a nurse at a community health centre in London, Ontario. Part of the health centre was a health outreach project for people experiencing homelessness, where I spent some of my time.

The building itself served as an election polling station, which I observed in action for the federal elections in 2004 and 2006 and for the provincial election in 2007. Staff at the health centre directly assisted individuals during the voting process by obtaining letters of residence, often from an emergency shelter, to verify their address. Furthermore, the centre hosted ID clinics throughout the week in which individuals would complete necessary paperwork in order to replace lost or stolen identification. This could include obtaining a waiver for the cost of the replacement or providing direct funding to cover the costs. In addition to residency letters and ID replacement, on the day of the election, staff at the centre could also vouch for individuals who did not have photo identification. At the time, this vouching process was an approved alternative to photo ID or ID with a current address. Lastly, the centre further supported the vouching process by asking anyone going to vote if they could wait for a bit and see if anyone else wanted to vote but needed someone to vouch for them. 


\section{The Canadian Journal of Critical Nursing Discourse}

See it. Speak it. Write it. Change it.

\section{The Case}

Before 2015, in Canada, individuals were required under the Elections Act to produce two pieces of ID, one being a government-issued photo ID containing proof of address, and the other could either be their voter identification card (VIC) or a second piece of government ID. The centre would pre-register individuals who were interested in voting by using the centre's address and in return their VIC would be mailed directly to the centre. Approximately a month prior to election day, staff would make it a priority to distribute these cards to the interested voters. On Feb $4^{\text {th }}, 2014$, the Government of Canada under Stephen Harper introduced Bill C23, the Fair Elections Act (Government of Canada, 2014), which proposed a number of changes. First, they proposed the elimination of vouching completely. This meant that there was no vouching for an individual's identification or their address. The rationale for the change in this legislation was weak, with statistics skewed by definitions rather then reflective of the reality of what was actually occurring. The government reported that there were approximately 15,000 "irregular votes" that were registered in the 2011 federal election (Neufeld, 2013). This figure and the associated terminology are quite striking and would seem to indicate a significant flaw in the election process.

However, what was occurring was that every use of vouching or a letter of attestation of residence was required to be noted as an irregular vote. Therefore, while individuals were properly following alternative measures under the Elections Act, their votes were tabulated as an irregular vote. Therefore, the government created a narrative of irregular votes, hinting at potential wide-spread fraud, and used this as an explanation for the need for electoral reform (Wherry, 2014).

Second to the removal of the vouching process, the Government of Canada proposed to remove the VIC as one of the two eligible pieces of ID. ID requirements would now include two pieces of identification apart from the VIC (Government of Canada, 2014). Of these two pieces of government-issued ID, at least one required a picture and at least one required a current address.

As a counter to concerns raised about this change, they expanded the number of pieces of identification that could be utilized. For instance, they added a hunting or fishing licence, credit card, property tax assessment or other such identification. However, these failed to satisfy concerns in terms of access to voting for those experiencing homelessness. A key concern for individuals experiencing homelessness is the complete loss of identification (Jones, Shier, \& Graham, 2013) and simply increasing the types of documents and identification considered for voting purposes does nothing to solve the issue.

Several community organizations in London, Ontario, including the London Homeless Coalition (LHC) and Neighbourhood Legal Services (NLS), were concerned about the proposed legislation and how it could create barriers to voting for individuals in the community. Collaboratively, the LHC and NLS wrote a letter of concern to local Members of Parliament identifying how such changes to voting would affect a significant portion of the community, more than just individuals experiencing homelessness. Seniors who may be moving into a supportive living environment or who are in a supportive living environment are another group who might lack the ID required to vote. Students who are attending school outside of their voting area may find it difficult to gain access to the legally recognized Canadian identification required to vote. This can be if ID has been left behind at a family home, if they have not changed their address on their identification, or if they have simply never had 2 pieces of government-issued ID. This letter expressed that there was a strong concern that changes in the legislation were going to disproportionately affect particular subpopulations of Canadians and be a barrier to them accessing their Constitutional right to participate in democracy. 
Craig Scott, a Member of Parliament for the opposition party, and a member of the Procedure and House Affairs Committee (PROC) that was reviewing the Bill was copied on the letter. He replied promptly and requested that the letter be forwarded to the PROC, which was done (Parliament of Canada, 2014a). He then invited one of us to appear as an expert witness to the PROC on April $9^{\text {th }}, 2014$. I was given this task, partly due to availability, so prepared myself to go to Ottawa to present. I was given five minutes before the PROC to express our concerns and advocate for more equitable voters' rights. I shared with the committee the reality of individuals experiencing homelessness and how easy it is lose one's identification as a result of one's social situation and environment (Parliament of Canada, 2014b). I shared that unexpected moves, theft, crime, misplacement, the "shelter shuffle", and the daily struggle of carrying everything you own with you are just some of the reasons individuals experiencing homelessness are so often without ID. I also mentioned that there are significant barriers to replacing ID. These barriers include the duration of time it takes to replace ID, replacing ID's can be costly, and requiring some form of identification to replace another piece of identification. Additionally, the precarious nature of someone struggling with homelessness and other challenges can significantly affect their ability to meet the demands of our timed society, including meeting predetermined hours of community-based organizations or completing forms if there is a literacy or language barrier. Therefore, removing the option to vouch for people in place of providing ID would particularly affect this segment of the population.

Apart from the discussion of ID, there were concerns discussed at the PROC regarding the letter of attestation of residence used at that time. The wording in the letter stated that a shelter staff member was confirming that an individual "ordinarily resided" at such-and-such address. This language of "ordinarily residing" was deemed to be problematic in the context of a population that may change residence on a nightly basis. There were also restrictions to the types of professionals who could complete this attestation form such as nurses and registered social workers. Therefore, apart from the vouching and ID issues, the letter of attestation of residence was also discussed with some promise made to consider revisions.

In spite of my testimony and the testimony of others as "expert witnesses" before the PROC, the revised Elections Act, now called the Fair Election Act, was confirmed by federal parliamentary vote on June 19, 2014. This result was fairly predictable given that the government of the time was a majority government. The only small change that came out of the process were the promised revisions to the letter of attestation of residence (Election Canada, 2015). This included removing the wording around "ordinarily residing at" and opening up who could complete this form.

While some concern was raised during the process of reviewing the legislation, the amount of public interest and concern grew with the confirmation of the legislation and attendant media articles (Williams, et al, 2014). Student groups, advocates for older adults, and advocates for those experiencing homelessness all expressed concerns in a variety of public sites that this legislation would disproportionately impact select groups of marginalized Canadians. This led to activist organizations and lawyers, led by the Council of Canadian and the Canadian Federation of Students, connecting to work together to oppose the legislation. On March 2015 a constitutional challenge was opened against the Fair Elections Act, for which I was asked to create an affidavit replicating my testimony to the PROC. An affidavit is a sworn statement of facts, provided in writing, and is admissible as legal evidence.

No initial reply to the challenge was received from the federal government and the next federal election was confirmed for October 2015. Therefore, an injunction was filed by our group in an attempt to prevent the implementation of the Fair Elections Act for this election (Nicol, 
2015a). The injunction was based on the fact that the Act was under a constitutional challenge, therefore should not be implemented. This injunction requested precipitated a more immediate response from the government, so government lawyers were provided with the opportunity to cross-examine all those who had submitted and affidavit for the challenge.

In June 2015, myself and the others were called to Toronto where we were separately crossexamined by government lawyers under oath, pertaining to the submitted affidavits. I personally expected the lawyers to raise questions about the barriers to accessing ID for individuals

experiencing homelessness, the key factors of our concern; however, I was caught off guard by their apparent objective to instead diminish us as "expert witnesses". This is interesting because the "expert witness" categorization was not one that I self-ascribed, but rather the designation given automatically to all those testifying at the PROC. So, the cross-examination involved the lawyers exploring everything I had written and published as an academic or on my blog, and statements I had made in the media. For example, they found a small error I had made in the literature review of my dissertation where I referred to a study as Canadian that was actually American. They spent hours and hours of examination not discussing anything to do with voting rights and experiences of homelessness but questioning the quality of my scholarship and objectivity of my public activism. This was an incredibly difficult experience for which I was ill prepared.

In the summer of 2015 federal courts rejected the injunction (Nicol, 2015b). The rationale was not related to the particular strengths of one argument or the other, but rather that elections materials had already been produced and training had been provided to elections officers utilizing the processes indicated in the Fair Elections Act. Therefore, it was not perceived to be feasible to revert to the prior legislation in time for the October election. This decision was subsequently appealed but our appeal was denied.
While advocacy to that point had limited effect, there was a significant change with the October 2015 election: A new majority government was elected, a Liberal government under Justin Trudeau. Liberal leaders were familiar with our advocacy efforts and concerns and had stated that they would be revising the Fair Elections Act, although the constitutional challenge remained open. As anticipated, the new federal government introduced Bill C-33 as a proposed new Elections $A c t$, which included reintroducing the vouching system. Unfortunately, Bill C-33 was not advanced and died with the end of a parliamentary session, which meant that by February 2018 we had decided to continue with our constitutional challenge to the still current Fair Elections Act. This led to a seemingly contradictory situation whereby lawyers of the government of the time were defending a bill introduced by the former government, which the current government had promised to change but hadn't. That said, re-initiating the challenge was enough to motivate the Liberal government to reintroduce a Bill to reform the Elections Act, Bill C-76. Success was achieved in December of 2018, as Bill C-76 was voted into law and reintroduced the voter information card as a piece of identification (Aiello, 2019). It also reintroduced the process of vouching and it maintained the improved letter of attestation of residence (Aiello, 2019). While the requirements under this new Act remained for two pieces of ID, one piece of ID could be the VIC. Our advocacy group was satisfied with the proposed changes and withdrew our legal challenge.

\section{Challenges of Advocacy}

Returning to the consideration of public policy advocacy being a competency required of nurses, this case provides some examples of the challenges that nurses may face in these endeavours. These challenges should both be considered by practicing nurses considering public policy advocacy as well as supporting undergraduate curricula designed to cover nursing competencies. Three challenges were identified through our advocacy efforts: 
1. When considering the breadth of the determinants of health and the necessity to view public policy intersectionally, $a$ vast scope of potential public policy issues fall within the scope of nursing's concern. The case presented herein is a good example of this challenge as the right to vote differs from determinants such as safe housing and access to income that are direct causal factors of poor health if lacking.

Therefore, it should be cautioned that policy issues of potential concern are nearly limitless. This is not to suggest that nurses should arbitrarily restrict themselves to certain domains of policy advocacy, but rather to suggest that effectiveness of policy advocacy will perceivably decline if individuals or groups have too many simultaneous campaigns to give the required energy to any single initiative. Reutter and Duncan (2002) note that the broader the policy domains considered by nurses, the broader the required knowledge background becomes.

2. Public policy advocacy is a political process. As such carries the risk that significant focus will be put on the messenger in addition to or instead of on the message (Levine, 2017). In this case, all who testified with concerns regarding the legislation were subject to being personally challenged for creditability by the lawyers representing the Government of Canada. This can be an emotionally troubling experience and nurse advocates should be prepared for such situations.

3. Public policy is public. It can, therefore, make the nurse's stance on controversial issues known to others, including colleagues, employers, friends, family, and in an online environment, disagreeable strangers. Should a public policy advocacy effort make it into traditional or social media channels, the nurse may be identified and should be prepared to be known for their position on the issue. News articles, submissions to government, or even published petitions almost all exist indefinitely online. Therefore, any position on a policy concern should be considered as permanently attached to one's name.

\section{Recommendations for Nurses as Advocates}

While at times challenging, nurses are required to be competent in engaging in public policy advocacy for social justice. The following are four recommendations to support nurses to do advocacy well:

1. Partaking in public policy advocacy is a journey that requires patience. At times in the case presented this included the monotony of again and again revising the same statement that was initially included in our February 2014 letter. At other times it was waiting months and months for responses from opposing lawyers to our various submissions. At times it was hard to even keep track of the current status of the process and what form of legal investigation was occurring, such as a challenge, and injunction, or an appeal. Nurses engaged in public policy advocacy should be prepared to follow the work through policy cycles that have been acknowledged to encompass extended time frames (Howlett, Ramesh, \& Perl, 2009).

2. There has to be a supportive and collaborative team in place to support advocacy work. In the case above, the advocacy group included interested and expert lawyers, advocates who can speak to the experiences of marginalized individuals and be willing to provide this level of advocacy under oath, and those representing the affected communities. Because the individuals involved can change over time with the length of the process, maintaining a collaborative 
See it. Speak it. Write it. Change it.

bond was key and this was facilitated by clear and positive communications from the lead lawyer. Coalitions, formal or informal, are a key platform for effective policy change (Sabatier, 1988).

3. Follow your 'ethical knowing' and speak out when you have a concern. Ethical knowing is the sense that nurses have when something is immoral, unjust, or otherwise wrong. One letter of concern can have a ripple effect and, ultimately, create change in policy and laws. Nurses who speak up have had social media posts, tweets, and other news stories leveraged in ways that ultimately transform public policy. The more nurses can continue to advocate and speak up for those who are often voiceless, the more likelihood we will have an impact in policy realms.

4. The importance of nurses to participate in voting cannot be understated. In order for our advocacy group to achieve the legislative change in the case above, the government ultimately had to change. It can be said then that sometimes the government makes the change(s) you ask of them, and other times there is a change in government. Voting, while not being advocacy per say, is one small way by which all nurses can be politically active. The impact of this action can be enhanced through collective action to vote that may include analyses of political policy platforms by nurses and shared with nurses, or even specific recommendations for voting by networks or coalitions of nurses legally able to do so.

\section{Conclusion}

While the call for nurses to be advocates is clear and strong (Contreras, 2011; National League of Nursing, 2019), resources for how to do so are limited. Indeed, much that has been written on how to do nursing advocacy is focused on advocating for individual clients within healthcare environments (Hanks, 2008). However, it is clear that as nurses, we are tasked by our professional associations to engage in public policy advocacy work for social justice. It is an important part of our role to listen to our clients, identify their challenges, and create strong advocacy efforts to effect policy and social change that meet their needs. Advocacy by nurses, especially within community health contexts, should be bold in approaching the true upstream structures that harm people experiencing various vulnerabilities such as homelessness. Through this case reflection there is a noted gap between the competency requirement and educational resources provided to nurses either in baccalaureate programs or available for nurses in practice. Next steps within the profession should include evidence-based teaching resources on how to engage in public policy advocacy as nurses. Developing learning outcomes for this domain might be a good first step in integrating practical content into nursing curricula.

To conclude, nurses indeed need to advocate across all of the broad determinants of health and be open to seeing and hearing where our advocacy is necessary. In this way we serve as witnesses, those who speak truth to the experiences of others. However, nurses must be provided with the resources needed to be able to do public policy advocacy effectively and safely. 


\section{References}

Aiello, R. (2019). Vouching, voter ID, advertising: How new elections law changes impact you. Retrieved Aug 122019 from https://www.ctvnews.ca/politics/vouching-voterid-advertising-how-new-elections-law-changesimpact-you-1.4461951.

Anderson, C. (2018). One person, no vote: How voter suppression is destroying our democracy. Bloomsbury Publishing.

Avolio, C. D. (2014). Political advocacy: Beliefs and practices of registered nurses (Unpublished Masters thesis). University of Windsor, Windsor, Ontario.

Barrett-Sheridan, S. E. (2009). A quantitative correlational study of political behavior and attitudes of nurses toward macro-social patient advocacy (Doctoral dissertation). University of Phoenix, Phoenix, Arizona.

Benton, D. (2012). Advocating globally to shape policy and strengthen nursing's influence. The Online Journal of Issues in Nursing, 17(1): 5.

British Columbia College of Nursing Professionals (2018). Competencies in the Context of Entry Level Registered Nurse Practice in British Columbia. Retrieved Aug 12 2019 from https://www.bccnp.ca/becoming a_nurse/Documents/RN_entry_level_competen cies_375.pdf.

Buck-McFadyen, E., \& MacDonnell, J. (2017). Contested practice: Political activism in nursing and implications for nursing education. International Journal of Nursing Education Scholarship, 14(1), 1-13.

Canadian Nurses Association (2017). Code of Ethics for Registered Nurses. 2017 Edition. Ottawa: Author.

College of Nurses of Ontario (2014). Entry-toPractice Competencies for Registered Nurses. Retrieved Aug 122019 from http://www.cno .org/globalassets/docs/reg/41037 entrytopracitic final.pdf.

Contreras, B. (2011). Education and advocacy. American Journal of Nursing, 111(7), 12-13.

Crowe, C., \& Baker, N. (2007). Dying for a home: Homeless activists speak out. Toronto: Between the Lines.

Gaetz, S. \& Dej, E. (2017). A New Direction: A Framework for Homelessness Prevention.

Toronto: Canadian Observatory on Homelessness Press.

Government of Canada (2014). C-23 An Act to amend the Canada Elections Act and other Acts and to make consequential amendments to certain Acts. Retrieved Aug 122019 from https://www.parl.ca/LegisInfo/BillDetails.aspx? billId $=6398775 \&$ Language $=E \& M o d e=1$.

Hanks, R. G. (2008). The lived experience of nursing advocacy. Nursing Ethics, 15(4), 468477.

Howlett, M., Ramesh, M., \& Perl, A. (2009). Studying public policy: Policy cycles and policy subsystems (Vol. 3). Oxford: Oxford University Press.

Jones, M. E., Shier, M. L., \& Graham, J. R. (2013). Social exclusion and self-esteem: The impact of the identity-bureaucracy nexus on employed people experiencing homelessness in Calgary, Canada. Journal of International and Comparative Social Policy, 29(2), 134-142.

Kerr, D. L., Van Wasshenova, E., Mahas, R., Everhart, F. J., Thompson, A., \& Boardley, D. (2017). Advocacy and public policy perceptions and involvement of master certified health education specialists. Health Promotion Practice, 18(5), 706-714.

Levine, D. S. (2017). Wisdom, Not Noise: The Law Professor as Policy Influencer. Wake Forest Law Review Online, 7, 1-11. 
Lyons, J. C., Webster, S. R., Friedman, B. L., Schiavoni, S. P., Lit, K. R., \& Cash, R. E. (2015). A preliminary study exploring the efficacy of advocacy training. Professional Psychology: Research and Practice, 46(6), 409413.

Marcuse, P. (1988). Neutralizing homelessness. Socialist Review, 18(1), 69-96.

National League of Nursing (2019). Advocacy Teaching: Nursing Is Social Justice Advocacy. Retrieved Aug 12, 2019 from http://www.nln. org/professional-development-programs/ teaching-resources/toolkits/advocacy-teaching.

Neufeld, H. (2013). Compliance Review: Final report and Recommendations. A Review of Compliance with Election Day Registration and Voting Process Rules. Retrieved Aug 12, 2019 from https://www.elections.ca/res/cons/comp/ crfr/pdf/crfr_e.pdf.

Nicol, J. (2015a). Fair Elections Act ID rules block voting, groups argue in court challenge. Retrieved Aug 12, 2019 from https://www.cbc. $\mathrm{ca} /$ news/canada/fair-elections-act-id-rulesblock-voting-groups-argue-in-court-challenge1.3136431 .

Nicol, J. (2015b). Federal election 2015: Voter ID rules stand, judge rules. Retrieved Aug 12, 2019 from https://www.cbc.ca/news/politics /federal-election-2015-voter-id-rules-standjudge-rules-1.3156519.

Parliament of Canada (2014a). Standing Committee on Procedure and House Affairs, Evidence, April 9, 2014. Retrieved Aug 12, 2019 from https://www.ourcommons.ca/Document Viewer/en/41-2/PROC/meeting-31/evidence.

Parliament of Canada (2014b). Meeting No. 31 PROC - Standing Committee on Procedure and House Affairs. Retrieved Aug 12, 2019 from https://www.ourcommons.ca/webcast/41-2/ PROC/31.
Reutter, L., \& Duncan, S. (2002). Preparing nurses to promote health-enhancing public policies. Policy, Politics, \& Nursing Practice, 3(4), 294-305.

Reutter, L., \& Kushner, K. E. (2010). 'Health equity through action on the social determinants of health': Taking up the challenge in nursing. Nursing Inquiry, 17(3), 269-280.

Ruth, T., Matusitz, J., \& Simi, D. (2017). Ethics of disenfranchisement and voting rights in the US: Convicted felons, the homeless, and immigrants. American Journal of Criminal Justice, 42(1), 56-68.

Sabatier, P. A. (1988). An advocacy coalition framework of policy change and the role of policy-oriented learning therein. Policy Sciences, 21(2-3), 129-168.

Sparks, T. (2017). Neutralizing Homelessness, 2015: Tent cities and ten year plans. Urban Geography, 38(3), 348-356.

Wherry, A. (2014). The cases for and against vouching. Retrieved Aug 12, 2019 from https://www.macleans.ca/politics/ottawa/thecases-for-and-against-vouching/.

Williams, M., Dawood, Y., Cameron, M., Deveaux, M., Fuji Johnson, G., \& Lenard, P. (2014). An open letter on the Fair Elections Act. Retrieved Aug 12, 2019 from https://www. theglobeandmail .com/opinion/an-open-letterfrom-academics-on-bill-c-23/article18114166/. 